\title{
Analisis Sistem Tataniaga Cabai Merah di Desa Besakih, Kecamatan Rendang, Kabupaten Karangasem
}

\author{
PUTU SRI ADNYASARI, RATNA KOMALA DEWI, KETUT BUDI SUSRUSA
}

\author{
Program Studi Agribisnis, Fakultas Pertanian, Universitas Udayana \\ Jl. PB. Sudirman Denpasar 80323 \\ Email: adnyasari@yahoo.com \\ ratnadewi61@ymail.com
}

\begin{abstract}
Analysis of Red Chili Trading System in Besakih Village, Rendang Sub-District of Karangasem Regency
\end{abstract}

Besakih village as one of the centers of red chilli production in Karangasem Regency has several marketing channels with different prices between producers and consumers. This study aims to investigate the channels of trading, commercial institutions, and the red chili trading system in the Village of Besakih. The data used were quantitative and qualitative data. The analysis used descriptive qualitative. Respondents in the study were 38 farmers determined by proportional random sampling method and 23 respondents of trading institutions determined by snowball sampling method. The research result was six channels of trading system, (1) Farmers - Local Assembly Trader's - Retailers - Consumers; (2) Farmers - Local Assembly Trader's - Retailers - Consumers; (3) Farmers - Sub Terminal of Agribusiness - Retailers - Consumers; (4) Farmers - Sub Terminal of Agribusiness Retailers - Consumers; (5) Farmers - Sub Terminal of Agribusiness - Consumers; (6) Farmers - Sub Terminal of Agribusiness - Market in Lombok. The most efficient trading channel was channel II. The trading agency consists of local assembly trader's / inter-city / inter-district traders, Sub Terminal of Agribusiness / inter-city / inter-district / inter island traders, traditional market retailers and supermarket retailers. Each of the trading system institution involved the three main functions of exchange, physical function and facility function. However, the activities undertaken by each institution were different.

Keywords: trading, institution, functions, red chili

\section{Pendahuluan}

\subsection{Latar Belakang}

Cabai merupakan salah satu komoditas sayuran yang memiliki peranan penting dan menjadi kebutuhan sehari-hari masyarakat Indonesia. Faktanya setiap hari masyarakat Indonesia memerlukan cabai sebagai pendamping makanan pokoknya (BPS, 2015).

Cabai memiliki nilai ekonomi yang tinggi dan mempunyai daya adaptif yang tinggi karena dapat tumbuh di dataran tinggi maupun di dataran rendah. Cabai merah 
diusahakan di tujuh kabupaten di Bali. Produksi cabai merah di Kabupaten Karangasem adalah terbesar kedua setelah Kabupaten Bangli dengan rata-rata produksi 22.136 ton/tahun (23,36\%). Beberapa desa di Kecamatan Rendang mengusahakan cabai merah, sehingga Kecamatan Rendang menjadi kecamatan penghasil cabai merah tertinggi di Kabupaten Karangasem dengan produksi rata-rata 15.679 ton/tahun (70,90\%) (Dinas Tanaman Pangan Hortikultura dan Perkebunan Propinsi Bali, 2017).

Desa Besakih merupakan salah satu penghasil cabai merah yang memiliki berbagai saluran tataniaga di Kecamatan Rendang. Setiap saluran memiliki sistem yang berbeda. Pada beberapa saluran terdapat perbedaan lembaga tataniaga yang terlibat, fungsi tataniaga yang dilakukan, perbedaan harga yang diterima petani, serta harga di tingkat pengecer akhir. Keadaan ini mempengaruhi nilai marjin tataniaga, farmer's share, dan efisiensi operasional. Penelitian mengenai Analisis Sistem Tataniaga Cabai Merah di Desa Besakih, Kecamatan Rendang, Kabupaten Karangasem penting dilakukan.

\subsection{Rumusan Masalah}

Berdasarkan latar belakang diatas, maka rumusan masalahnya adalah

1. Saluran tataniaga cabai merah di Desa Besakih, Kecamatan Rendang, Kabupaten Karangasem.

2. Lembaga tataniaga yang terlibat dalam sistem tataniaga cabai merah di Desa Besakih, Kecamatan Rendang, Kabupaten Karangasem.

3. Fungsi-fungsi tataniaga yang ada dalam sistem tataniaga cabai merah di Desa Besakih, Kecamatan Rendang, Kabupaten Karangasem.

\subsection{Tujuan Penelitian}

Berdasarkan rumusan masalah diatas, maka tujuan penelitian adalah untuk mengetahui

1. Saluran tataniaga cabai merah di Desa Besakih, Kecamatan Rendang, Kabupaten Karangasem.

2. Lembaga tataniaga cabai merah di Desa Besakih, Kecamatan Rendang, Kabupaten Karangasem.

3. Fungsi-fungsi tataniaga cabai merah di Desa Besakih, Kecamatan Rendang, Kabupaten Karangasem.

\section{Metode Penelitian}

\subsection{Lokasi dan Waktu Penelitian}

Penelitian ini dilakukan di Desa Besakih, Kecamatan Rendang, Kabupaten Karangasem dan dilaksanakan pada bulan Februari sampai dengan bulan Maret 2017. Pemilihan lokasi dilakukan dengan metode purposive (sengaja) dengan pertimbangan Desa Besakih merupakan salah satu daerah sentra produksi cabai merah di Kabupaten Karangasem. 


\subsection{Metode Pengumpulan Data dan Variabel Penelitian}

Penelitian ini dilakukan dengan survei. Pengumpulan data dilakukan dengan metode observasi dan wawancara. Variabel-variabel yang dianalisis pada penelitian ini adalah saluran tataniaga, lembaga tataniaga, dan fungsi-fungsi tataniaga. Saluran tataniaga dianalisis efisiensinya secara kuantitatif terhadap marjin tataniaga, farmer's share, dan efisiensi opersional.

\subsection{Populasi dan Sampel}

Populasi dalam penelitian ini adalah seluruh petani cabai merah di Desa Besakih dan lembaga tataniaga cabai merah yang bersumber dari Desa Besakih. Petani di Desa Besakih terdiri atas 61 orang, dimana sebanyak 37 orang anggota Kelompok Tani Merta Sari dan 24 orang anggota Kelompok Tani Sari Gumitir. Berdasarkan Rumus Slovin diperoleh 38 orang sampel petani. Rumus Slovin adalah

$$
\mathrm{n}=\frac{\mathrm{N}}{1+\mathrm{Ne}^{2}}
$$

Keterangan:

$\mathrm{n} \quad=$ ukuran sampel atau jumlah responden

$\mathrm{N} \quad=$ ukuran populasi

$\mathrm{e} \quad=$ presentasi kelonggaran ketelitian kesalahan pengambilan sampel sebesar $10 \%$.

Responden petani pada penelitian ini ditentukan dengan teknik Propotional Random Sampling dengan rumus sebagai berikut (Arikunto, 2014).

$$
\mathrm{n}=\frac{\mathrm{x}}{\mathrm{N}} \mathrm{x} \mathrm{N}
$$

Keterangan:

$\mathrm{n} \quad$ : jumlah sampel yang diinginkan setiap strata

$\mathrm{N} \quad$ : jumlah seluruh populasi petani cabai merah di desa besakih

$\mathrm{X} \quad$ : jumlah populasi petani pada setiap kelompok tani

$\mathrm{N}_{1} \quad$ : sampel

Berdasarkan rumus tersebut diperoleh jumlah responden pada Kelompok Tani Merta Sari sebanyak 23 petani dan Kelompok Tani Sari Gumitir sebanyak 15 petani. Penentuan responden lembaga menggunakan metode snowball yang diawali dari informasi pedagang yang membeli cabai merah pada petani sampel diperoleh 23 responden lembaga pemasaran.

\subsection{Metode Analisis}

Efisiensi tataniaga dianalisis secara kuantitatif terhadap marjin tataniaga, farmer's share, dan efisiensi operasional. Saluran tataniaga, lembaga tataniaga, dan fungsi-fungsi tataniaga cabai merah di Desa Besakih dianalisis dengan menggunakan metode deskriptif kualitatif. Lembaga tataniaga yang terlibat dalam proses tataniaga 
ini lebih lanjut diidentifikasikan sebagai tengkulak, pedagang besar, agen penjualan, dan pengecer. Terdapat tiga fungsi utama tataniaga yaitu fungsi pertukaran, fungsi fisik, dan fungsi penyediaan sarana.

Margin tataniaga pada setiap lembaga tataniaga dirumuskan sebagai berikut (Sudiyono, 2002).

$$
\mathrm{M}=\operatorname{Pr}-\mathrm{Pf}
$$

Keterangan :

$\mathrm{M}=$ Margin tataniaga

$\operatorname{Pr}=$ Harga di tingkat lembaga tataniaga

Pf $=$ Harga di tingkat petani

Menurut Susrusa (2016), bagian yang diterima petani merupakan persentase harga yang diterima petani dari harga yang dibayar konsumen (harga eceran).

Menghitung share (bagian) harga yang diterima petani dihitung dengan rumus :

$$
\mathrm{Fsi}=\frac{\mathrm{Pf}}{\mathrm{Pr}} \times 100 \%
$$

\section{Keterangan :}

Fsi = Persentase yang diterima petani

Pf = Harga di tingkat petani

Pr $\quad=$ Harga di tingkat konsumen

Efisensi operasional diukur dengan rasio keluaran pemasaran (output) terhadap masukan pemasaran (input) (Downey dan Erickson, 1992)

$$
\mathrm{EO}=\frac{\text { Output }}{\text { Input }}
$$

Keterangan:

Output $=$ Harga yang dibayar konsumen (Rp/unit)

Input $=$ Total Biaya Pemasaran (Rp/unit)

\section{Hasil dan Pembahasan}

\subsection{Saluran Tataniaga}

Badan atau lembaga yang menyelenggarakan penyaluran barang dari produsen ke konsumen merupakan saluran tataniaga (Saefuddin, 1996). Saluran tataniaga dibagi menjadi dua sistem penyaluran suatu produk ke konsumen yaitu (1) Petani menjual langsung produknya ke konsumen tanpa melalui lembaga tataniaga, (2) Petani menjual produknya ke konsumen melalui lembaga tataniaga (Kohls dan Uhl, 
1998). Hasil penelitian menunjukkan terdapat enam saluran tataniaga cabai merah di Desa Besakih, Kecamatan Rendang, Kabupaten Karangasem sebagai berikut.

1. Petani $\rightarrow$ Pedagang Pengumpul $\rightarrow$ Pengecer (Pedagang Pasar Kreneng, Denpasar) $\rightarrow$ Konsumen

2. Petani $\rightarrow$ Pedagang Pengumpul $\rightarrow$ Pengecer (Pedagang Pasar Galiran, Klungkung) $\rightarrow$ Konsumen

3. Petani $\rightarrow$ Sub Terminal Agribisnis $\rightarrow$ Pengecer (Pedagang Pengecer Pasar Galiran, Klungkung) $\rightarrow$ Konsumen

4. Petani $\rightarrow$ Sub Terminal Agribisnis $\rightarrow$ Pasar Swalayan Tiara $\rightarrow$ Konsumen

5. Petani $\rightarrow$ Sub Terminal Agribisnis $\rightarrow$ Konsumen

6. Petani $\longrightarrow$ Sub Terminal Agribisnis $\rightarrow$ Pasar di Lombok

Hasil panen cabai merah sebanyak $121.500 \mathrm{~kg}$ dari responden dijual ke pedagang pengumpul tingkat desa sebanyak $93.650 \mathrm{~kg}(77,08 \%)$ dan $\mathrm{ke}$ Sub Terminal Agribisnis (STA) di Desa Besakih yang sekaligus sebagai pedagang antar kota, antar kabupaten dan antar pulau sebanyak $27.850 \mathrm{~kg}$ (22,92\%), seperti pada gambar 1 berikut.

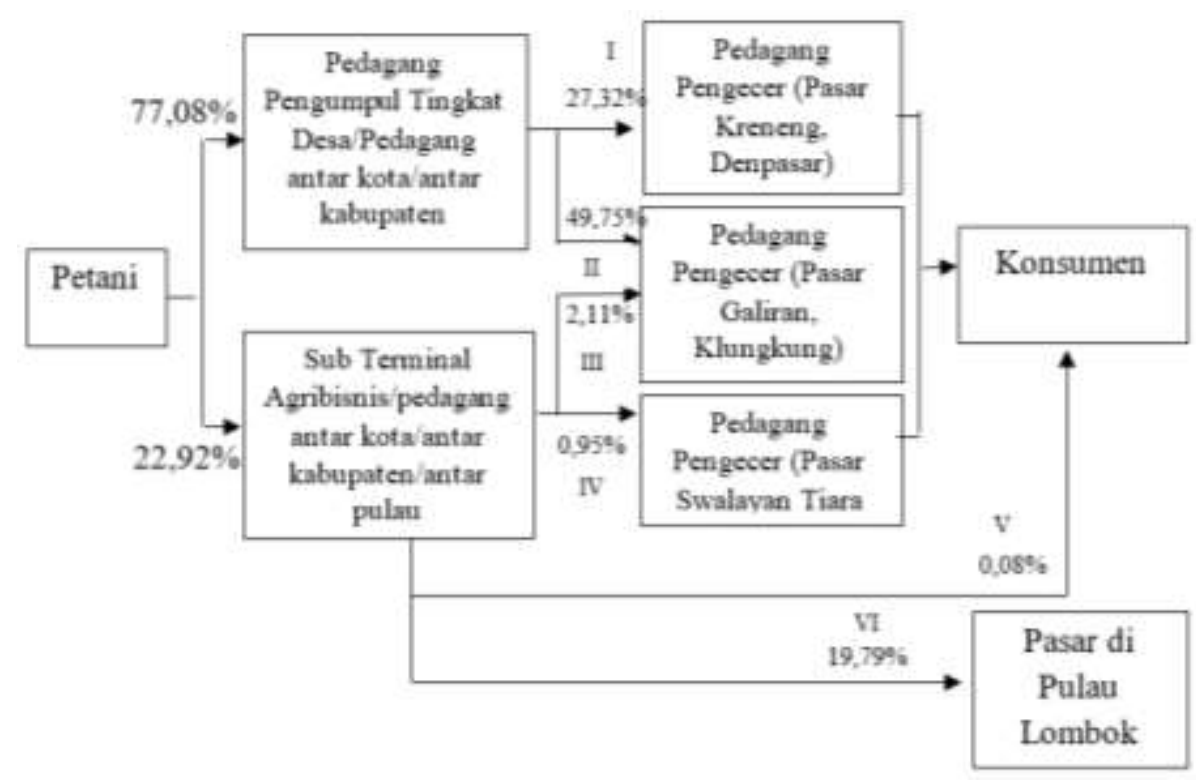

Gambar 1.

Saluran Tataniaga Cabai Merah di Desa Besakih, Kecamatan Rendang, Kabupaten Karangasem

Efisiensi keenam saluran tataniaga tersebut dapat dilihat pada tabel 1. 


\section{Tabel. 1}

Analisis Margin Tataniaga, Farmer's Share dan Efisiensi Operasional pada Saluran Tataniaga Cabai Merah di Desa Besakih, Kecamatan Rendang,

Kabupaten Karangasem

\begin{tabular}{|c|c|c|c|c|}
\hline No & Saluran Tataniaga & $\begin{array}{l}\text { Margin } \\
\text { Tataniaga } \\
\text { (Rp/kg) }\end{array}$ & $\begin{array}{c}\text { Farmer's } \\
\text { Share } \\
(\%)\end{array}$ & $\begin{array}{c}\text { Efisiensi } \\
\text { Operasional } \\
(\%)\end{array}$ \\
\hline I & $\begin{array}{l}\text { Petani } \\
\text { Pedagang pengumpul } \\
\text { Pengecer (Pedagang Pasar } \\
\text { Kreneng,Denpasar) } \\
\text { Konsumen }\end{array}$ & 6.000 & 75,00 & 770,84 \\
\hline II & $\begin{array}{l}\text { Petani } \\
\text { Pedagang pengumpul } \\
\text { Pengecer (Pedagang Pasar Galiran, } \\
\text { Klungkung) } \\
\text { Konsumen }\end{array}$ & 5.000 & 78,26 & $1.242,46$ \\
\hline III & $\begin{array}{l}\text { Petani } \\
\text { STA } \\
\text { Pengecer (Pedagang Pasar Galiran, } \\
\text { Klungkung) } \\
\text { Konsumen }\end{array}$ & 5.000 & 78,26 & $1.229,29$ \\
\hline IV & $\begin{array}{l}\text { Petani } \\
\text { STA } \\
\text { Pasar Swalayan Tiara } \\
\text { Konsumen }\end{array}$ & 16.000 & 55,55 & 765,96 \\
\hline V & $\begin{array}{l}\text { Petani } \\
\text { STA } \\
\text { Hotel }\end{array}$ & 20.000 & 50,00 & 135,27 \\
\hline VI & $\begin{array}{l}\text { Petani } \\
\text { STA } \\
\text { Pasar di Lombok }\end{array}$ & 6.000 & 75,00 & $1.090,91$ \\
\hline
\end{tabular}

Sumber : Data primer diolah (2017)

Pada tabel 1 masing-masing saluran tataniaga cabai dalam penelitian ini, baik saluran tataniaga I, II, III, IV, V, dan VI memiliki nilai margin tataniaga yang berbeda-beda. Nilai margin tataniaga berpengaruh terhadap nilai dari farmer's share dan efisiensi operasionalnya. Saluran tataniaga yang paling efisien adalah saluran II yaitu dengan margin tataniaga sebesar $\mathrm{Rp}$ 5.000,00 menghasilkan farmer's share sebesar 78,26\% dan efisiensi operasional tertinggi yaitu $1.242,46 \%$.

\subsection{Lembaga Tataniaga}

Lembaga tataniaga adalah badan usaha atau individu yang menyelenggarakan tataniaga, menyalurkan jasa dan komoditi dari produsen kepada konsumen akhir serta mempunyai hubungan dengan badan usaha atau individu lainnya (Sudiyono, 2002). Tataniaga cabai merah di Desa Besakih melibatkan lembaga tataniaga pedagang pengumpul tingkat desa, Sub Terminal Agribisnis Manik Mekar Nadi di 
Desa Besakih, enam pedagang pengecer yang terdapat di Pasar Galiran Klungkung, satu di Pasar Galiran Denpasar, dan satu pedagang pengecer di pasar modern (Pasar Swalayan Tiara, Denpasar).

Pedagang pengumpul desa adalah pedagang pengumpul cabai merah yang berada di Desa Besakih. Adanya kedekatan hubungan kekerabatan atau kekeluargaan antara pedagang pengumpul dengan petani. Pedagang pengumpul desa juga memiliki kedekatan hubungan (hubungan kerabat) dengan pedagang-pedagang yang terdapat di Pasar Galiran Klungkung, sehingga informasi harga pasar dengan mudah diketahui melalui telephone. Sistem pembayaran yang dilakukan pedagang pengumpul tingkat desa kepada petani yaitu langsung dibayar lunas.

STA Manik Mekar Nadi di Desa Besakih merupakan salah satu STA yang terdapat di Propinsi Bali. STA Manik Mekar Nadi menyerap hasil produksi petani dan membantu memasarkan hasil produksi petani ke luar kabupaten, luar kota, hingga luar pulau. STA Manik Mekar Nadi bekerja sesuai dengan manfaat STA pada umumnya, namun sasaran utama pembangunan STA belum tercapai sepenuhnya. Dilihat dari volume penjualan cabai merah lebih banyak diserap oleh pedagang pengumpul desa $(77,08 \%)$ dibandingkan oleh STA $(22,92 \%)$.

Pedagang pengecer adalah pedagang yang membeli cabai di pedagang pengumpul tingkat desa maupun yang membeli di STA Manik Mekar Nadi. Terdapat tiga orang pengecer di Pasar Galiran Kabupaten Klungkung yang membeli cabai merah pada pedagang pengumpul desa, tiga orang pedagang pengecer di Pasar Galiran Klungkung yang membeli pada STA, satu orang pedagang pengecer di Pasar Kreneng Denpasar, dan satu orang pedagang pengecer di pasar swalayan yang membeli produk dari STA Manik Mekar Nadi .

\subsection{Fungsi-Fungsi Tataniaga}

Fungsi tataniaga adalah proses atau jasa yang dibutuhkan untuk memberikan suatu produk guna bentuk, waktu, tempat, dan pemilikan yang diinginkan konsumen (Branson and Douglas, 1983). Ada tiga tipe fungsi tataniaga yaitu fungsi pertukaran, fungsi fisik, dan fungsi fasilitas (Downey dan Erickson, 1992). Secara umum fungsifungsi tataniaga yang dilakukan setiap lembaga pada tataniaga cabai merah di Desa Besakih, Kecamatan Rendang, Kabupaten Karangasem diuraikan pada tabel 2. 
Tabel 2.

Fungsi Tataniaga Setiap Lembaga Tataniaga Cabai Merah di Desa Besakih, Kecamatan Rendang, Kabupaten Karangasem

\begin{tabular}{|c|c|c|c|c|c|}
\hline \multicolumn{2}{|c|}{ Fungsi Pemasaran } & \multicolumn{4}{|c|}{ Lembaga } \\
\hline Fungsi & Aktivitas & $\begin{array}{c}\text { Pedagang } \\
\text { Pengumpul } \\
\text { Tingkat } \\
\text { Desa/pedagang } \\
\text { antar kota/antar } \\
\text { kabupaten }\end{array}$ & $\begin{array}{c}\text { STA (pedagang } \\
\text { antar kota/antar } \\
\text { kabupaten/antar } \\
\text { pulau }\end{array}$ & $\begin{array}{c}\text { Pedagang } \\
\text { Pengecer } \\
\text { Pasar } \\
\text { Tradisional }\end{array}$ & $\begin{array}{l}\text { Pengecer } \\
\text { Pasar } \\
\text { Swalayan }\end{array}$ \\
\hline \multirow{3}{*}{ Pertukaran } & Penjualan & $\checkmark$ & $\checkmark$ & $\checkmark$ & $\checkmark$ \\
\hline & Pembelian & $\checkmark$ & $\checkmark$ & $\checkmark$ & $\checkmark$ \\
\hline & Kontrak & - & $\checkmark$ & - & $\checkmark$ \\
\hline \multirow{2}{*}{ Fisik } & Pengangkutan & $\checkmark$ & $\checkmark$ & $\checkmark$ & $\checkmark$ \\
\hline & Penyimpanan & - & - & $\checkmark$ & $\checkmark$ \\
\hline \multirow{5}{*}{$\begin{array}{l}\text { Penyediaan } \\
\text { Sarana }\end{array}$} & Informasi & & & & \\
\hline & Pasar & $\checkmark$ & $\checkmark$ & $\checkmark$ & $\checkmark$ \\
\hline & Penanggungan & & & & \\
\hline & Resiko & $\checkmark$ & $\checkmark$ & $\checkmark$ & $\checkmark$ \\
\hline & $\begin{array}{l}\text { Standarisasi dan } \\
\text { grading }\end{array}$ & - & $\checkmark$ & - & $\checkmark$ \\
\hline
\end{tabular}

Sumber: diolah dari data primer

\section{Simpulan dan Saran}

\subsection{Simpulan}

1. Terdapat enam saluran tataniaga cabai merah di Desa Besakih, yaitu

a. Petani $\rightarrow$ Pedagang Pengumpul $\rightarrow$ Pengecer (Pedagang Pasar Kreneng, Denpasar) $\rightarrow$ Konsumen

b. Petani $\rightarrow$ Pedagang Pengumpul $\rightarrow$ Pengecer (Pedagang Pasar Galiran, Klungkung) $\rightarrow$ Konsumen

c. Petani $\rightarrow$ Sub Terminal Agribisnis $\rightarrow$ Pengecer (Pedagang Pengecer Pasar Galiran, Klungkung) $\rightarrow$ Konsumen

d. Petani $\rightarrow$ Sub Terminal Agribisnis $\rightarrow$ Pasar Swalayan Tiara $\rightarrow$ Konsumen

e. Petani $\rightarrow$ Sub Terminal Agribisnis $\rightarrow$ Konsumen

f. Petani $\rightarrow$ Sub Terminal Agribisnis $\rightarrow$ Pasar di Lombok

Saluran tataniaga yang menguntungkan petani yaitu saluran II, karena saluran II memiliki margin tataniaga terendah ( $\mathrm{Rp} 5.000,00)$, farmer's share tertinggi $(78,26 \%)$, nilai efisiensi operasional tertinggi $(1.242,46 \%)$.

2. Lembaga tataniaga terdiri atas 14 orang pedagang pengumpul tingkat desa/pedagang antarkota/antar kabupaten, satu orang STA/pedagang antar kota/antar kabupaten/antar pulau, delapan orang pedagang pengecer yang terdiri atas tujuh orang pengecer pasar tradisional dan satu pengecer pasar swalayan. 
3. Setiap lembaga tataniaga yang terlibat melakukan ketiga fungsi utama yaitu fungsi pertukaran, fungsi fisik, dan fungsi fasilitas. Namun, aktivitas yang dilakukan oleh tiap lembaga berbeda.

\subsection{Saran}

Berdasarkan simpulan tersebut maka saran yang dapat diambil adalah (1) Petani cabai merah di Desa Besakih, Kecamatan Rendang, Kabupaten Karangasem sebaiknya menggunakan saluran tataniaga II dalam memasarkan hasil produksinya, karena saluran tataniaga II paling efisien dan (2) Sub Terminal Agribisnis Manik Mekar Nadi diharapkan dapat memperluas tataniaga cabai merah dengan konsumen hotel dan pasar swalayan, sehingga dapat menyerap lebih banyak cabai dengan kualitas dan harga lebih tinggi.

\section{Ucapan Terimakasih}

Ucapan terimakasih penulis tujukan kepada semua pihak yang telah membantu penulis dalam melaksanakan penelitian hingga karya ilmiah ini dapat dipublikasikan dalam e-jurnal.

\section{Daftar Pustaka}

Arikunto. 2014. Prosedur Penelitian Suatu Pendekatan Praktik. PT Rineka Cipta. Jakarta.

Badan Pusat Statistik. 2015. Analisis Tematik ST2013 Subsektor Efesiensi Sistem Produksi dan Tataniaga Hortikultura. www.media.neliti.com. Diunduh pada tanggal 20 November 2016

Branson and Douglas. 1983. Introduction to Agricultural Marketing. Mc Graw-Hill Book Company. New York. USA

Dinas Tanaman Pangan dan Hortikultura. 2017. Produksi Cabai Merah di Provinsi Bali 2011 sd 2015. Provinsi Bali

Downey dan Erickson. 1992. Manajemen Agribisnis. Penerbit Erlangga. Jakarta

Kohls, Richard 1. and Joseph N. Uhl. 1998. Marketing of Agricultural Products. Prentice Hall. New Jersey.

Saefuddin. 1996. Tata Niaga Pertanian. Program Pasca sarjana Universitas Padjadjaran Bandung. Bandung.

Sugiyono. 2011. Metode Penelitian Kuantitatif, Kualitatif, dan R\&D. Alfabeta. Bandung

Susrusa, Budi. 2016. Bahan Ajar Tataniaga Pertanian. Program Studi Agribisnis. Fakultas Pertanian Universitas Udayana. Denpasar. UNUD

Sudiyono, Armand. 2002. Tataniaga Pertanian. Universitas Muhammadiyah Malang Press. Malang 